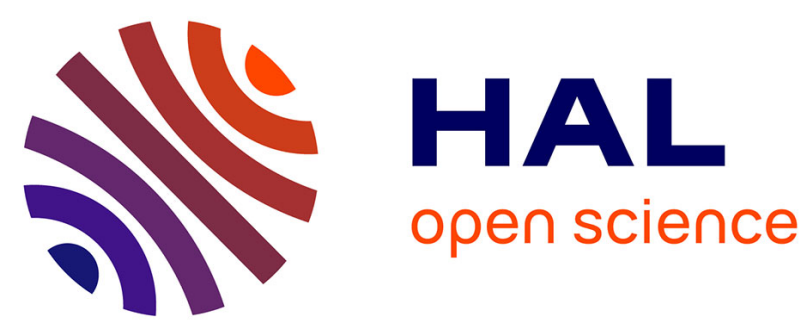

\title{
Oxygen isotopic exchange: A useful tool for characterizing oxygen conducting oxides
}

Jean-Marc. Bassat, P. Petitjean, Jacques Fouletier, Cécile Lalanne, C. Caboche, Fabrice Mauvy, Jean-Claude Grenier

\section{- To cite this version:}

Jean-Marc. Bassat, P. Petitjean, Jacques Fouletier, Cécile Lalanne, C. Caboche, et al.. Oxygen isotopic exchange: A useful tool for characterizing oxygen conducting oxides. Applied Catalysis A : General, 2005, 289 (1), pp.84-89. 10.1016/j.apcata.2005.04.054 . hal-00015495

\section{HAL Id: hal-00015495 https://hal.science/hal-00015495}

Submitted on 8 Dec 2005

HAL is a multi-disciplinary open access archive for the deposit and dissemination of scientific research documents, whether they are published or not. The documents may come from teaching and research institutions in France or abroad, or from public or private research centers.
L'archive ouverte pluridisciplinaire HAL, est destinée au dépôt et à la diffusion de documents scientifiques de niveau recherche, publiés ou non, émanant des établissements d'enseignement et de recherche français ou étrangers, des laboratoires publics ou privés. 


\title{
Oxygen isotopic exchange: A useful tool for characterizing oxygen conducting oxides
}

\author{
Bassat J .-M., Petitjean M., Fouletier J., Lalanne C., Caboche G., Mauvy F., Grenier J .-C.
}

\section{Abstract :}

The ${ }^{18} \mathrm{O} /{ }^{16} \mathrm{O}$ isotope exchange depth profile technique (IEDP) followed by SIMS characterizations was applied to dense membranes of pure ionic conductors and mixed ionic/electronic conducting materials. It is a very useful tool since we obtain in both cases data concerning the oxygen diffusion in the bulk and the oxygen exchange at the surface of the materials. Comparisons were done, including results concerning the role of the surface with regards to the oxygen reduction reaction. Detailed experimental and analytical processes are given.

Keywords : SOFC; Mixed conducting oxides; Oxygen transport properties; Oxygen reduction

\section{Introduction}

In order to enhance the performances of solid oxide fuel cells (SOFCs) at moderate temperature (typically $700^{\circ} \mathrm{C}$ ), it is needful to improve significantly the electrocatalytic properties of the cathode materials, which requires to better understand the limiting factors of the oxygen reduction. Various solutions have been considered, one of them consists in using mixed ionic and electronic conducting materials (namely MIEC). The triple phase boundary process (TPB) which is usually the limiting step, is replaced by a double interface (DI) gas phase-cathode-electrolyte process which is supposed to promote the electrocatalytic reactions and to lower the cathode polarization. In this way, $\left(\mathrm{La}_{0.8} \mathrm{Sr}_{0.2}\right)\left(\mathrm{Mn}_{1}-{ }_{y} \mathrm{Fe}_{y}\right) \mathrm{O}_{3} \pm \delta$ perovskites (namely LSMF) and $\mathrm{Ln}_{2}-{ }_{x} \mathrm{Sr}_{x} \mathrm{MO}_{4}+\delta(\mathrm{Ln}=\mathrm{La}, \mathrm{Nd}, \mathrm{Pr}$; $\mathrm{M}=\mathrm{Ni}, \mathrm{Fe}, \mathrm{Cu}, \mathrm{Co}$ ) overstoichiometric compounds have been recently investigated for the development of intermediate temperature SOFCs (ITSOFCs) [1], [2], [3], [4], [5], [6], [7] and [8]. For characterizing such materials, the measure of the ionic conductivity contribution with respect to the total one, which is mainly electronic, remains a difficulty.

The BIMEVOX compounds $\left(\mathrm{Bi}_{4} \mathrm{~V}_{2(1-x)} \mathrm{Me}_{2 x} \mathrm{O}_{11}-{ }_{3 x}\right)$, often referred to as BIMEVOX (ME $=\mathrm{Bi}$, $\mathrm{Cu}$ or Co) exhibit an oxygen ion conductivity larger than other classical oxide electrolytes (yttria stabilized zirconia or ceria-based solid solutions for instance), at low temperatures (typically at $500-600{ }^{\circ} \mathrm{C}$ ) [9] and [10]. However, an important point concerns the low catalytic activity of these oxides towards the oxygen reduction reaction [11].

In both cases (pure ionic and MIEC materials), the oxygen diffusion coefficient $D^{*}$, which is directly correlated to the ionic conductivity, and the surface exchange one $(k)$ are the relevant parameters for characterizing these materials.

Various techniques can be used but the ${ }^{18} \mathrm{O} /{ }^{16} \mathrm{O}$ isotope exchange appears a particularly efficient method: it was early proposed by Muzykantov et al. in the 1970 s for studying the kinetics and mechanism of oxygen exchange on the surface of binary oxide catalysts [12], [13], [14] and [15]. They proposed mechanisms for the heteroexchange of $\mathrm{O}_{2}$ as well as for the homoexchange.

Later on, in the 1980s, the isotope exchange depth profile (IEDP) method was developed by Steele et al. [16] and more recently by Kilner et al. [17], [18] and [19]. They used the ${ }^{18} \mathrm{O} /{ }^{16} \mathrm{O}$ isotope exchange for studying the oxygen diffusion properties in solid oxides exhibiting high ionic (or mixed) conductivity. After analysing the ${ }^{18} \mathrm{O}$ concentration depth profile by secondary ion mass spectroscopy (SIMS), they calculated the oxygen diffusion coefficient $D^{*}$ and the surface exchange one $(k)$.

We report in this paper, data concerned with the oxygen diffusion and the oxygen exchange coefficients of various ceramic membranes using this technique. Characteristic compositions of the materials quoted above have been selected: two MIEC oxides, $\mathrm{La}_{2} \mathrm{NiO}_{4}+\delta$ and $\left(\mathrm{La}_{0.8} \mathrm{Sr}_{0.2}\right) \mathrm{FeO}_{3}-\delta$ (LSMF with $y=1$, namely LSF) and a pure (good) ionic conductor (BICOVOX.10;

$\left.\mathrm{Bi}_{4} \mathrm{~V}_{2(1-x)} \mathrm{CO}_{2 x} \mathrm{O}_{11-3 x}\right)$.

\section{Experimental}




\subsection{Preparation of powders and polished dense pellets}

The BICOVOX.10 powders were synthesized by a co-precipitation method and supplied by Pharmacie Centrale de France (PCF). For the need of our experiments, they were previously ball-milled in ethanol for $3 \mathrm{~h}$ in order to obtain submicronic particles $\left(d_{50}=0.5 \mu \mathrm{m}\right)$.

The nickelate $\mathrm{La}_{2} \mathrm{NiO}_{4}+\delta$ was prepared using the nitrate-citrate route [7] and [8]. Stoichiometric amounts of rare-earth oxide, $\mathrm{La}_{2} \mathrm{O}_{3}$ (Strem), and nickel oxide (NiO) (Aldrich) were dissolved in dilute nitric acid. Citric acid was added during stirring in a large excess ( 3.3 moles per mole of $\mathrm{La}_{2} \mathrm{NiO}_{4}+\delta$ ). Then the solution was dehydrated at $120^{\circ} \mathrm{C}$ and slowly heated until self-combustion of the precipitates. They were then fired for $8 \mathrm{~h}$ in the temperature range of $950-1080{ }^{\circ} \mathrm{C}$. Powders were ground using an attritor at $1200 \mathrm{rpm}$ for $3 \mathrm{~h}$, in ethanol medium, and submicronic particles were obtained $\left(d_{50}=0.5 \mu \mathrm{m}\right)$.

The LSF perovskite samples were synthesized using the glycine-nitrate process, which allows to produce powders having a crystallite size smaller than $0.3 \mu \mathrm{m}$ [20]. Then the powder was pressed (uniaxial and isostatic dry pressing), without organic additives, into disc-shaped specimens. Pellets were sintered according to appropriate thermal cycles determined elsewhere [7], [11] and [21]. The final sintering temperatures were 750,1350 and $1400{ }^{\circ} \mathrm{C}$, for the BICOVOX.10, nickelate and LSF compounds, respectively. The relative densities of the ceramics were always higher than $95 \%$, as checked by the Archimede method.

It is known that the $k$ surface exchange coefficient could be sensitive to the surface state [22] as well as the oxygen partial pressure [23]. Therefore, a similar oxygen partial pressure was fixed at $P=0.21$ atm. of pure ${ }^{18} \mathrm{O}_{2}$ for each experiment. In addition, the preparation of the samples should be carried out meticulously in order to obtain a reproducible surface state. The ceramics were first abraded with silicon carbide papers of successive grades and endly polished with an alumina paste down to $1 / 4 \mu \mathrm{m}$. Such as-polished and highly dense ceramics (>95\%) were supposed not to show open porosity [24]. After the abrasion, the samples were cleaned in ethanol using ultrasounds. Such a procedure likely allows to compare the $k$ values for the three materials.

However, in the specific case of the BICOVOX.10 compounds, two pellets were systematically studied at various exchange temperatures: a first pellet without polishing the surfaces and a second one which was polished as described above. The results will be discussed in Section 3.

\subsection{Determination of the oxygen diffusion and surface exchange coefficients ( ${ }^{*}$, k): detailed experimental process}

The oxygen diffusion and surface exchange coefficients ( $D^{*}$ and $k$, respectively) were measured using the so-called ${ }^{18} \mathrm{O} /{ }^{16} \mathrm{O}$ IEDP method. The experiment involves to anneal the sample in an isotopically enriched gas during a given time, and then to determine the resulting penetration profile of the isotope within the sample using secondary ion mass spectroscopy (SIMS).

The samples were set in a silica tube heated by a "roll-on" furnace. Each part of the set-up is made of an appropriately polished stainless steel. A special attention was paid to avoid traces of moisture in the set-up: room temperature high vacuum pumping (down to less than $5 \times 10^{-3} \mathrm{~Pa}$ ) was performed before each step of the experiments. Prior to exchange with ${ }^{18} \mathrm{O}_{2}$, the samples were annealed in unlabelled oxygen $\left({ }^{16} \mathrm{O}_{2}\right.$ with natural isotopic abundance, $\left.99.75 \%\right)$ for more than $70 \mathrm{~h}$, under the similar conditions (pressure and temperature) as for the subsequent diffusion annealing. This pre-annealing which lasts at least 10 times longer than the ${ }^{18} \mathrm{O}_{2}$ one, ensures a thermodynamical equilibrium of the sample at the same temperature and pressure as the exchange anneal; consequently, the measured diffusion coefficient will be the tracer diffusion coefficient $D^{*}$.

After thermal quenching, the apparatus was again evacuated, and isotopically labelled oxygen $\left({ }^{18} \mathrm{O}_{2}\right.$, CEA, Euriso - top 97\%) was introduced in the chamber $\left(P_{\text {total }}=2.1 \times 10^{4} \mathrm{~Pa}\right)$. The exchange anneal involved the following steps: fast heating of the samples by rolling the preheated furnace over the sample chamber, a dwell at a constant temperature for the required duration of the anneal, and then quenching the sample by rolling back the furnace. Once the samples were cooled down, the labelled oxygen was cryogenically recovered.

Note that the (labelled or unlabelled) oxygen was first introduced at room temperature at the pressure $P \sim 1 \times 10^{4} \mathrm{~Pa}$, which, upon heating, increased up to about $P \sim 2 \times 10^{4} \mathrm{~Pa}$ at $T=600^{\circ} \mathrm{C}$. The final pressure was adjusted to $P \sim 2.1 \times 10^{4} \mathrm{~Pa}$. 
The exchange temperatures were in between 500 and $900^{\circ} \mathrm{C}$, which is the range of the operating temperature of such oxides in fuel cell devices.

The exchange times were chosen with respect to the following criteria: provided that the $D^{*}$ value is approximately known, one can estimate the diffusion length $L_{\mathrm{D}}$ from the relation, $L_{\mathrm{D}}=2 \sqrt{D^{\prime} t}$, where $t$ is the exchange time. The value of $L_{D}$ should be about a few tens of micrometers in order to allow a good refinement of the $D^{*}$ and $k$ values. In any case, one has to check experimentally that the profiles obtained from both sides of the pellet do not overlap, which could artificially increase the ${ }^{18} \mathrm{O}$ content in the material, and consequently the values of the coefficients. The nominal content $(0.2 \%)$ should be found in the bulk of the ceramic.

The SIMS instruments used in this work for determining the ${ }^{18} \mathrm{O}$ concentration, were: (i) a CAMECA IMS ( $4 f+6 f$ facilities) ion microprobe with a $\mathrm{Cs}^{+}$ion beam (used for the studies of $\mathrm{La}_{2} \mathrm{NiO}_{4}+\delta$ and BiCoVOX.10 oxides), (ii) a Riber MIQ256 with an $\mathrm{Ar}^{+}$ion beam (used for the studies of LSF oxides). The energy of the primary ion beam was about $10 \mathrm{keV}$. Both apparatus were equipped with a mass spectrometer.

Depending on the extent to which the labelled oxygen had penetrated the sample, different modes of operation have been employed.

For profile depths smaller than $5 \mu \mathrm{m}$, the profilometry mode was used from the surface to the bulk of the sample. This method was originally developed as the so-called "IEDP technique". The primary ion beam progressively erodes a small crater in the sample. The beam is then scanned over the sample in a square profile, over dimensions larger than several beam diameters, e.g. about $1 \mathrm{~mm}^{2}$. In addition, the surface of analysis represents about $10 \%$ of the abraded crater surface to avoid side effects (Fig. 1). The crater depth was determined by correlating abrasion time with laser profilometry (from UBM, USA).

For profile depths higher than a few tens of micrometer, prior to the SIMS analysis, all the pellets were cut with a low-speed diamond saw in two parts. One of them was coated with a metallic paste (Woods alloy) in such a way that its vertical section (which is perpendicular to the exchange surface) could be further analyzed. Consequently, for each sample, two symmetrical profiles can be recorded:

(i) for "intermediate" (50-250 $\mu \mathrm{m})$ penetration profiles, the surface scanning, a square with adjustable size (until $500 \mu \mathrm{m}$ ), was directly analyzed ( $I_{\text {m }} 2 \mathrm{pA}$ ). The result was first given as a mapping of the concentration of various ions $\left({ }^{16} \mathrm{O}^{-},{ }^{18} \mathrm{O}^{-}\right.$, etc.), displayed by a colour gradient (Fig. 2). In a second step, from the digitized image, the profile diffusion $\left({ }^{18} \mathrm{O} /\left({ }^{18} \mathrm{O}+{ }^{16} \mathrm{O}\right)\right.$ ratio, also called the normalized ${ }^{18} \mathrm{O}$ concentration) could be plotted as a function of the depth. This method has advantages in terms of analysis speed and measurement accuracy since the profile is deduced from a large number of data points.

(ii) for "deep" (>250 $\mu \mathrm{m}$ ) penetration profiles the linescan technique was used [25]. In such a case, the penetration profile was analyzed by laterally scanning the primary ion beam $(I \approx 10 \mathrm{pA})$ across the exposed surface, as a function of a pre-calibrated scanwidth. ${ }^{16} \mathrm{O}^{-}$and ${ }^{18} \mathrm{O}^{-}$secondary ion intensities were sequentially recorded.

All the analysed profiles show normal decays down to the natural abundance of ${ }^{18} \mathrm{O}_{2}(0.2 \%)$. The samples were sufficiently thick $(2-3 \mathrm{~mm})$ in comparison with the tracer penetration depth, so that the present results can be analyzed using the model of diffusion into a semi-infinite medium.

The tracer diffusion parameters were determined by fitting appropriate solutions of the second Fick's law to the tracer isotope concentration profile. The solution of the diffusion equation for onedimensional diffusion into a semi-infinite medium has been given by Crank [26]:

$$
\begin{aligned}
C^{\prime}(x)= & \operatorname{erfc}\left(\frac{x \sqrt{D^{*} t}}{2}\right)-\exp \left(\frac{k}{D^{*}} x+\frac{k^{2}}{D^{*}} t\right) \\
& \times \operatorname{erfc}\left\{\left(\frac{x \sqrt{D^{*} t}}{2}\right)+\left(\frac{k}{D^{*}} \sqrt{D^{*} t}\right)\right\}
\end{aligned}
$$


with $\operatorname{erfc}(x)=\int_{0}^{x} \exp \left(-x^{2}\right) \mathrm{d} x$ and $C(x, t)=\frac{C(x, y)-C_{0}}{C_{\mathrm{s}}-C_{0}}$

$C(x, t)$ is the ${ }^{18} \mathrm{O}_{2}$ concentration in the solid obtained by SIMS at the depth $x, C^{\prime}(x, t)$ the isotopic fraction corrected for the natural isotopic background level (referred to as $C_{0}=0.2 \%$ ) and for the isotope enrichment of the gas (referred to as $C_{s}=97 \%$ ), $t$ the duration of the isotope anneal, $D^{*}$ the oxygen tracer diffusion coefficient, $k$ the surface exchange coefficient representing the oxygen reduction kinetics and $h$ is the ratio $k / D^{*}$.

Moreover, in some cases (especially at low temperatures and/or for poor ionic conductors), the ${ }^{18} \mathrm{O}_{2}$ depth profiles show extended tails, the shape of these tails is due to fast grain boundary diffusion. To take into account this intergranular diffusion via the grain boundaries, an additional term is used: $A_{\mathrm{gb}} \exp \left(-Z_{\mathrm{gb}} x^{6 / 5}\right)$, where $A_{\mathrm{gb}}$ and $Z_{\mathrm{gb}}$ are fitted tailing function parameters. One can also fit such profiles using either the Le Claire's equation [25] or the expression proposed by Chung et al. [27]. This latter is derived from the exact Whipple's solution [28], the fitted parameter being the grain boundary diffusion coefficient $D_{\mathrm{gb}}^{*}$. This fit has been performed in the case of LSMF compounds $(y=0.2$ and 0.5$)$, the results have been reported elsewhere [21] and [29].

Eq. (1) simply shows that the exchange kinetics at the gas/solid interface is proportional to the ${ }^{18} \mathrm{O}$ concentration difference between the gas phase and the surface of the material. It is then necessary the ${ }^{18} \mathrm{O}$ concentration to be kept constant as a function of time.

\section{Results and discussion}

The diffusion profiles obtained for the two BICOVOX.10 (polished or unpolished) ceramics using the linescan technique are almost identical; a typical one is shown in Fig. 3 . The figure also displays the result of the non-linear regression analysis used to determine $D^{*}$ and $k$. It can be seen that the shape of the experimental profile is in good agreement with that calculated from Eq. (1). Two anneal durations under labelled oxygen atmospheres were tested: 240 min, leading to an oxygen penetration up to $1000 \mu \mathrm{m}$ and 81 min resulting in an oxygen diffusion of $500 \mu \mathrm{m}$ (Fig. 3). Both series of experiments led to $D^{*}$ and $k$ values in good agreement. The results are given in Table 1 . At $600{ }^{\circ} \mathrm{C}$, the mean value of the tracer diffusion coefficient is $D_{\mathrm{mcy}}^{*}=6.5 \times 10^{-8} \mathrm{~cm}^{2} \mathrm{~s}^{-1}$, while the corresponding oxygen exchange coefficients is $k_{\text {moy }}=2.3 \times 10^{-8} \mathrm{~cm} \mathrm{~s}^{-1}$. The high values of the diffusion coefficient obtained in this work confirm that the BIMEVOX-type phases are excellent oxygen ionic conductors at low temperatures. In comparison, at $600{ }^{\circ} \mathrm{C}$, their anionic conductivity is two or three orders of magnitude higher than that of $8 \%$ mol doped zirconia (namely 8YSZ) [30].

As shown in Table 1, the exchange coefficient values obtained with or without polishing BICOVOX.10 ceramics are similar, at least within the experimental accuracy. Due to the fact that $k$ values are very small (about $10^{-8} \mathrm{~cm} \mathrm{~s}^{-1}$ at $T=600^{\circ} \mathrm{C}$ ), it must be pointed out that they did not significantly depend on the surface roughness of the material. From a qualitative point of view, such small $k$ values might have been anticipated when looking at the shape of the profile, and especially at the normalized ${ }^{18} \mathrm{O}$ concentration at $x=0$. Indeed, the low concentration (i.e. about $8 \times 10^{-3}$, Fig. 3) indicates that the exchange kinetics is dominated by a slow surface exchange step. Finally, these results are consistent with oxygen permeation experiments [31]. They showed that, in spite of a high oxygen diffusion coefficient, purely ionic BIMEVOX.10 materials have very poor electrocatalytic performances, which, unfortunately for applications such as the separation of molecular oxygen, is a serious drawback.

Fig. 4 shows the experimental and fitted profiles obtained for a polished ceramic of $\mathrm{La}_{2} \mathrm{NiO}_{4}+\delta$ exchanged at $600^{\circ} \mathrm{C}$ for $50 \mathrm{~min}$. The corresponding $D^{*}$ and $k$ values are given in Table 1 . These oxides with the two dimensional $\mathrm{K}_{2} \mathrm{NiF}_{4}$-type structure, exhibit $D^{*}$ and $k$ coefficients whose values are about one order of magnitude higher than those of the best perovskite materials, especially in the temperature range of $500-700{ }^{\circ} \mathrm{C}$ [7] and [8]. It should be noted in Fig. 4 that the normalized ${ }^{18} \mathrm{O}$ concentration for $x=0$ is much higher than the corresponding value obtained for the BICOVOX.10 oxide. It reaches about 0.4 against $8 \times 10^{-3}$, and correspondingly the $k$ value for $\mathrm{La}_{2} \mathrm{NiO}_{4}+\delta$ is higher than the one of BICOVOX.10.

Fig. 5 shows the depth profiles obtained for LSF, at various exchange temperatures. It can be observed that the oxygen diffusion is enhanced at increasing temperature. Typical $D^{*}$ and $k$ values deduced from the experimental curves are reported in Table 1 for $T=800^{\circ} \mathrm{C}$. Their oxygen diffusion coefficients are the smallest ones with regards to the three compounds studied in this work. 
However, the LSF compound $(y=1)$ is the best MIEC oxide of the LSMF family, probably because of an increased oxygen vacancies concentration [21]. One should also point out that the required

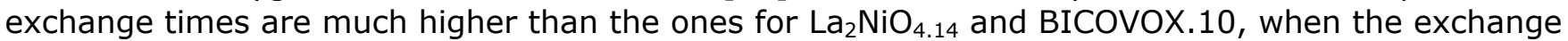
temperature is higher (Table 1 ). The $k$ values are intermediate between those of $\mathrm{La}_{2} \mathrm{NiO}_{4.14}$ and BICOVOX.10 ones. Once again, the normalized ${ }^{18} \mathrm{O}$ concentration for $d=0$ is very high when compared to Fig. 3, corresponding to the BICOVOX.10 with a low $k$ value. However, remember that this indication is purely qualitative. Finally, compared with other perovskites [21], LSF cathodes exhibit promising MIEC properties (i.e. high diffusion coefficient, $D^{*}$ and high surface exchange coefficient, $k$ ). Nevertheless, these materials are worse MIEC materials than $\mathrm{Ln}_{2} \mathrm{NiO}_{4}+\delta(\mathrm{Ln}=\mathrm{La}$, $\mathrm{Nd}, \mathrm{Pr})$ oxides from the point of view of electrocatalytic properties $(21,29)$.

The values of the activation energy of the oxygen diffusion of the nickelate as well as that of BICOVOX $(\approx 0.85 \mathrm{eV})$ are somewhat lower than that of the YSZ $(1.0 \mathrm{eV})$, and much lower than those of the perovskite materials ( $\approx 1.5 \mathrm{eV}$ for LSF for instance) [32]. Such features evidence that the oxygen diffusion is quite easy in these compounds, which could be correlated to their bidimensional structures, leading to preferential diffusion paths. Indeed, concerning the MIEC oxides with the $\mathrm{K}_{2} \mathrm{NiF}_{4}$-type structure, an oxygen exchange was performed on a high quality $\mathrm{La}_{2} \mathrm{NiO}_{4.14}$ single crystal using the IEDP process [33]. This work clearly showed the bi-dimensional character of the ionic conductivity: an important anisotropy of the oxygen diffusion was emphasized, the $D^{*}$ coefficient being about one to two orders of magnitude higher in the $(a, b)$ plane than along the perpendicular direction (// c-axis).

One have also to point out that in MIEC materials, a synergy between electronic and ionic conductions is supposed to occur [34].

According to Kilner et al., the exchange kinetics can be considered as rapid if the factor $\bar{h} \sqrt{D^{*} t}$ is higher than 4 [17]. None of the three compounds meets this value (Table 1); LSF appears to have the best exhange kinetics $\left(h \sqrt{D^{*} t} \approx 1\right)$. Conversely, the BiCovOX performances are very poor $\left(h \sqrt{D^{*} l} \approx 10^{-2}\right)$.

\section{Conclusion}

The ${ }^{18} \mathrm{O} /{ }^{16} \mathrm{O}$ isotopic exchange depth profile technique (IEDP) performed on dense ceramics and followed by secondary ion mass spectroscopy (SIMS) appears a very useful tool for characterizing the oxygen diffusion processes. It concerns the oxygen diffusion in the bulk (characterized by the $D^{*}$ coefficient) and the oxygen exchange at the surface of the materials ( $k$ coefficient). As shown in this work, this technique may be applied to pure oxygen ionic conductors. In the specific case of BIMEVOX-type compounds, in spite of high oxygen diffusion coefficients (and correspondingly high ionic conductivities), we have found that the electrocatalytic performances with respect to the molecular oxygen reduction are very poor. This technique may be also used for the determination of the small part of the ionic conductivity (with respect to the larger electronic one) in the case of MIEC (mixed ionic electronic conductors) materials. We were then able to compare the performances (in terms of $D^{*}$ and/or $k$ values) of two kinds of MIEC materials studied for future SOFCs cathode materials.

These studies may also concern single crystals with specific crystallographic orientations [33].

From a general viewpoint, our set up can also be used for total exchanges with ${ }^{18} \mathrm{O}$ and/or ${ }^{17} \mathrm{O}$, with the aim to perform NMR and Raman studies [35].

\section{References}

[1] M. Petitjean, G. Caboche, L.-C. Dufour and F. Morin In: J. Huijsmans, Editor, Proceedings of the Fifth European Solid Oxide Fuel Cell Forum, vol. 2 Lucerne (2002), pp. 351-358.

[2] M. Petitjean, G. Caboche, L.-C. Dufour, Solid State Ionics, in press.

[3] S.J. Skinner and J.A. Kilner, Ionics 5 (1999), p. 171. 
[4] V.V. Vashook, I.I. Yushkevich, L.V. Kokhanovsky, L.V. Makhnach, I.F. Kononyuk, H. Ullmann and H. Altenburg, Solid State Ionics 119 (1999), p. 23.

[5] S.J. Skinner and J.A. Kilner, Solid State Ionics 135 (2000), p. 709.

[6] V.V. Kharton, A.P. Viskup, A.V. Kovalesky, E.N. Naumovich and F.M.B. Marques, Solid State Ionics 143 (2001), p. 337.

[7] E. Boehm, J.-M. Bassat, M.C. Steil, P. Dordor, F. Mauvy and J.-C. Grenier, Solid State Sci. 5 (2003), pp. 973-981.

[8] E. Boehm, J.-M. Bassat, P. Dordor, F. Mauvy, J.-C. Grenier, P. Stevens, Solid State Ionics, in press.

[9] G. Mairesse In: B. Scrosati, Editor, Fast Ion Transport in Solids, Kluwer Acadamic Publishers, Dordrecht (1993), p. 271.

[10] M. Guillodo, J. Fouletier, L. Dessemond and P. Del Gallo, J. Eur. Ceram. Soc. 21 (2001), p. 2331.

[11] M. Guillodo, J.M. Bassat, J. Fouletier, L. Dessemond and P. Del Gallo, Solid State Ionics 164 (2003), p. 87.

[12] M. Blanchard, G. Louguet, G.K. Boreskov, V.S. Muzykantov and G.I. Panov, Bull. Soc., Chim. de France 3 (1971), p. 814.

[13] G.K. Boreskov and V.S. Muzykantov, Ann. NY Acad. Sci. 213 (1973), p. 137.

[14] V.S. Muzykantov, G.K. Boreskov and G.I. Panov, React. Kinet. Catal. Lett. 1 (1974) (3), p. 315.

[15] V.S. Muzykantov, V.V. Popovskii, G.K. Boreskov and N.I. Mikichu, Kinet. Kataliz 5 (1964) (4), p. 745.

[16] D.S. Tannhauser, J.A. Kilner and B.C.H. Steele, Nucl. Inst. Meth. Phys. Res. 218 (1983), p. 504.

[17] J.A. Kilner, B.C.H. Steele and L. Ilkov, Solid State Ionics 12 (1984), p. 12.

[18] B.C.H. Steele, J.A. Kilner, P.F. Dennis and D.S. Tannhauser, Ceramic surfaces and surface treatments. In: R. Morrel and G. Nicholas, Editors, Br. Ceram. Proc. 34 (1984), p. 53.

[19] J.A. Kilner, Proceedings of the Second International Symposium on Ionic and Mixed Conducting Membranes, vol. PV 94-12 The Electrochemical Society, Pennington, NJ (1994), p. 174.

[20] F. Morin In: P. Stevens, Editor, Proceedings of the Third European Solid Oxide Fuel Cell Forum Nantes (1998), pp. 193-200.

[21] M. Petitjean, O. Heintz, J.M. Bassat, G. Caboche, L.C. Dufour, Solid State Ionics, submitted for publication.

[22] J.N. Audinot, Ph.D. Thesis, Bordeaux 1 University, France, 1999.

[23] J.L. Routbort, R. Doshi and M. Krumpelt, Solid State Ionics 86- 88 (1996), p. 21.

[24] W.D. Kingery, H.K. Bowen and D.R. Uhlmann, Introduction to Ceramics, Wiley, New York (1976).

[25] A.D. Le Claire, Philos. Mag. 7 (1962), pp. 141-167.

[26] J. Crank (2nd ed.), The Mathematics of Diffusion, Oxford University Press, Oxford (1975). 
[27] Y.C. Chung and B.J. Wuensch, Mater. Lett. 28 (1996), p. 47.

[28] R.T.P. Whipple, Philos.Mag. 45 (1954), p. 1225.

[29] M. Petitjean, Ph.D. Thesis, Burgundy University, 2003.

[30] P.S. Manning, J.D. Sirman and J.A. Kilner, Solid State Ionics 93 (1997), p. 125.

[31] M. Guillodo, J. Fouletier, L. Dessemond and P. Del Gallo, J. Electrochem. Soc. 149 (2002), p. 193.

[32] B.C.H. Steele, Solid State Ionics 94 (1997), p. 239.

[33] J.M. Bassat, P. Odier, A. Villesuzanne, C. Marin and M. Pouchard, Solid State Ionics 167 (2004), p. 341.

[34] E. Boehm, Ph.D. Thesis, Bordeaux 1 University, France, 2002.

[35] B. Rousseau, J.M. Bassat, A. Blin, M.S. de Oliveira, P. Odier, C. Marin and P. Simon, Solid State Sci. 6 (2004), p. 1131. 


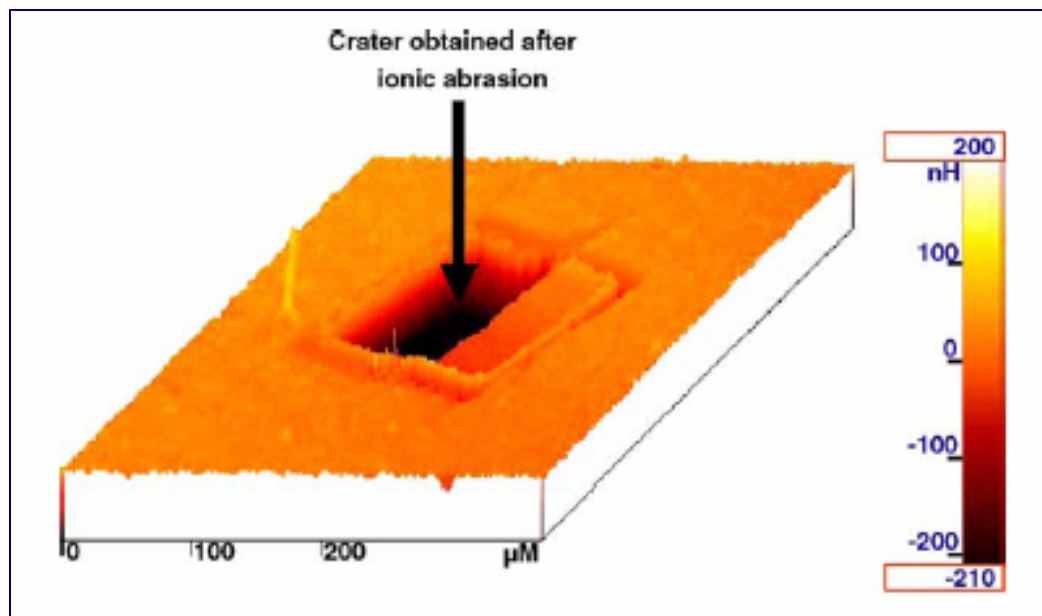

Fig. 1. Crater obtained after an ionic abrasion performed on LSF ceramic.

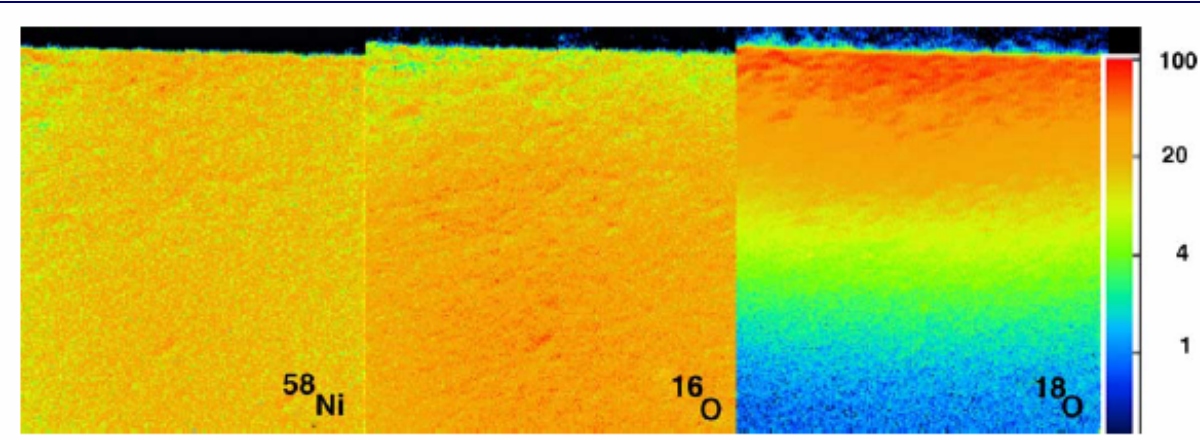

Fig. 2. SIMS images $\left({ }^{58} \mathrm{Ni},{ }^{16} \mathrm{O}\right.$ and $\left.{ }^{18} \mathrm{O}\right)$ of a polished ceramic of $\mathrm{La}_{2} \mathrm{NiO}_{4+8}$ after ${ }^{18} \mathrm{O}_{2}$ exchange annealing at $500{ }^{\circ} \mathrm{C}$ for $2 \mathrm{~h}$. Concentrations vary from $0 \%$ (blue colour) to $100 \%$ (red colour). (For interpretation of the references to colour in this figure legend, the reader is referred to the web version of the article.)

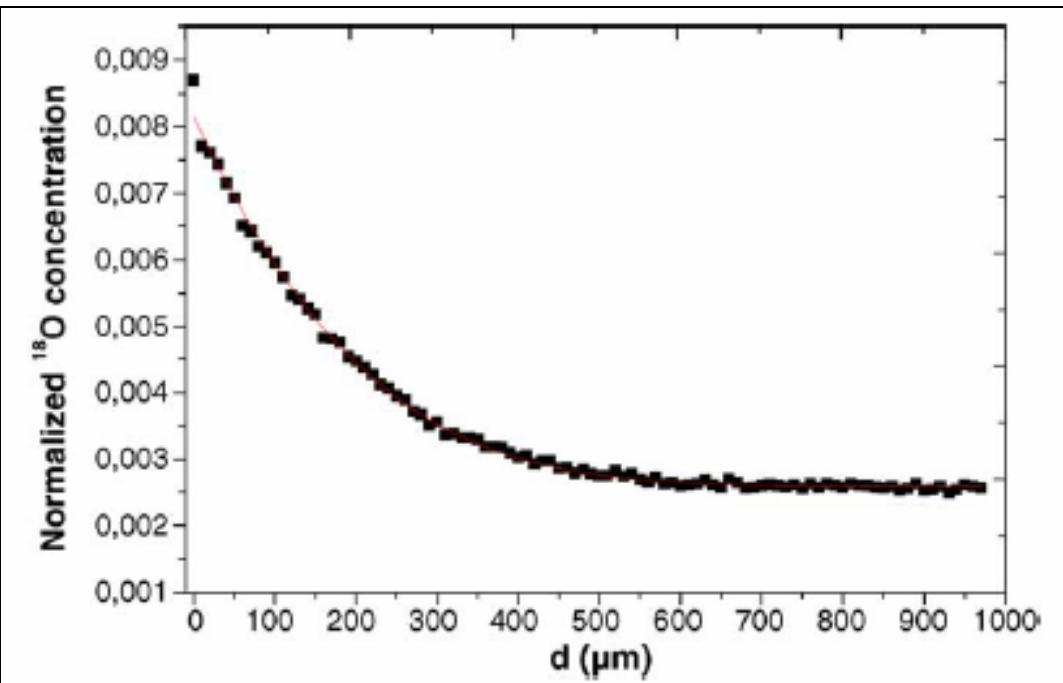

Fig. 3. Normalized ${ }^{18} \mathrm{O}$ concentration depth profile obtained by SIMS (linescanning) for a (polished or un-polished) ceramic of BICOVOX.10 exchanged at $600^{\circ} \mathrm{C}$ for $81 \mathrm{~min}$. 
Table 1

Diffusion and exchange coefficients of the studied materials determined using ${ }^{18} \mathrm{O} /{ }^{16} \mathrm{O}$ exchange method

\begin{tabular}{|c|c|c|c|c|c|}
\hline Annealing temperature $\left({ }^{\circ} \mathrm{C}\right)$ (exhange duration, $\min$ ) & Sample formulation & Surface state & $k\left(\mathrm{~cm} \mathrm{~s}^{-1}\right)$ & $D^{*}\left(\mathrm{~cm}^{2} \mathrm{~s}^{-1}\right)$ & $h \sqrt{\overline{D^{*} t}}$ \\
\hline $600(240)$ & BICOVOX.1 & Polished & $2.5 \times 10^{-8}$ & $5.3 \times 10^{-8}$ & $1.3 \times 10^{-2}$ \\
\hline $600(81)$ & BICOVOX.1 & Polished & $2.1 \times 10^{-8}$ & $8.7 \times 10^{-8}$ & $5 \times 10^{-3}$ \\
\hline $600(240)$ & BICOVOX.1 & Unpolished & $2.4 \times 10^{-8}$ & $4.8 \times 10^{-8}$ & $1.3 \times 10^{-2}$ \\
\hline $600(81)$ & BICOVOX.1 & Unpolished & $2.0 \times 10^{-8}$ & $7.5 \times 10^{-8}$ & $5 \times 10^{-3}$ \\
\hline $600(50)$ & $\mathrm{La}_{2} \mathrm{NiO}_{4}+8$ & Polished & $10^{-6}$ & $1 \times 10^{-8}$ & 0.55 \\
\hline $800(560)$ & LSF & Polished & $2.0 \times 10^{-7}$ & $1.5 \times 10^{-9}$ & 0.95 \\
\hline
\end{tabular}

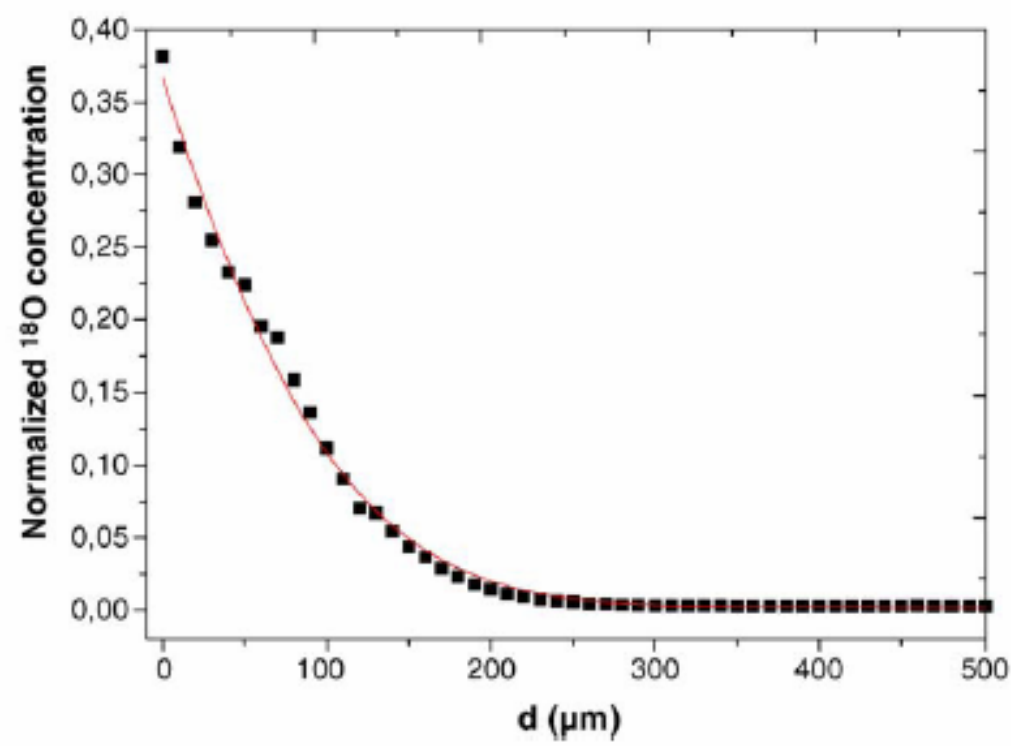

Fig. 4. Normalized ${ }^{18} \mathrm{O}$ concentration depth profile obtained by SIMS (linescanning) for a polished ceramic of $\mathrm{La}_{2} \mathrm{NiO}_{4}+8$ exchanged at $600^{\circ} \mathrm{C}$ for $50 \mathrm{~min}$.

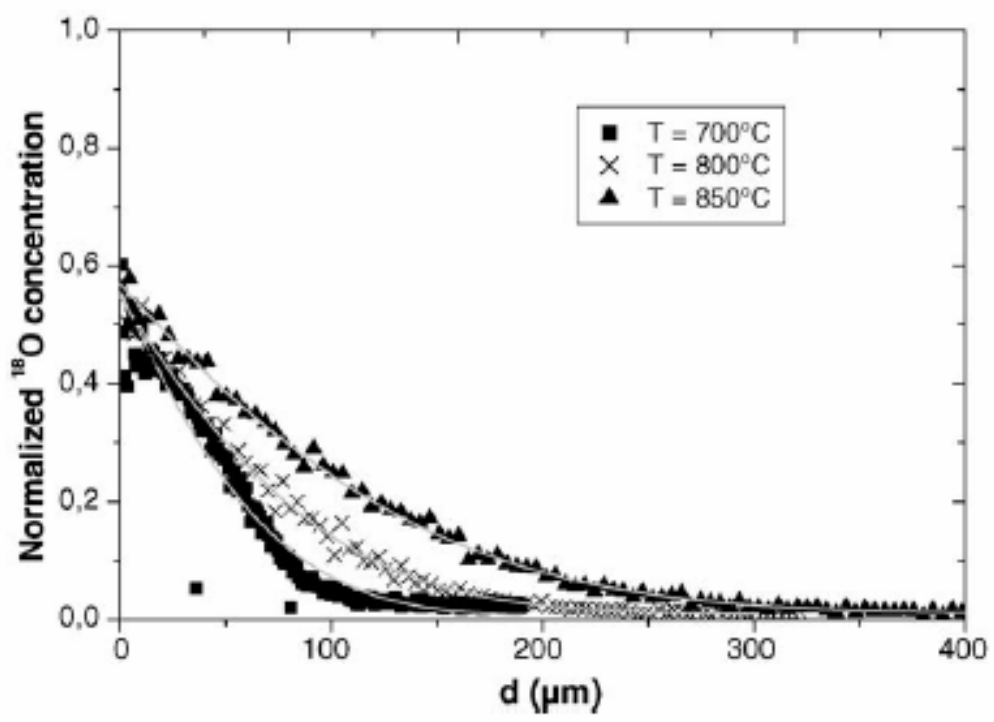

Fig. 5. Normalized ${ }^{18} \mathrm{O}$ concentration depth profiles obtained by SIMS (profilometry and linescanning) for polished ceramics of $\left(\mathrm{La}_{0.8} \mathrm{Sr}_{0.2}\right) \mathrm{FeO}_{3-8}$ exchanged at $700{ }^{\circ} \mathrm{C}(1200 \mathrm{~min}), 800^{\circ} \mathrm{C}(560 \mathrm{~min})$ and $850^{\circ} \mathrm{C}(525 \mathrm{~min})$. 